\title{
Comparative study of pain perception among infertile women undergoing Hysterosalpingography and Office Hysteroscopy in Port Harcourt, Nigeria
}

\author{
Nyengidiki Tamunomie $K^{*}$ and Oriji Vaduneme K \\ Department of Obstetrics and Gynaecology, University of Port Harcourt Teaching Hospital, Port Harcourt, Nigeria
}

\begin{abstract}
Background: Various methods of evaluation of uterine cavity during infertility workup do exist, among which are Hysteroscopy and Hysterosalpingography. These procedures are considered invasive and associated with pain mitigating utilization.

Objective: To determine pain perception following Hysteroscopy and Hysterosalpingography and patient preference based on pain grading.

Materials and methods: A cross-sectional comparative prospective study conducted among 101 infertile women undergoing Hysteroscopy and Hysterosalpingography Pain perceptions were assessed using a numerical pain scale after each procedure. Socio-demographic variables, pain experience categorization for both methods were collated. Descriptive statistics were computed for all relevant data and presented in tabular form and analyzed. A comparison of pain against the preferred method was made using a McNemar Chi-square test, and bivariate logistic regression analysis was conducted with $\mathrm{P} \leq 0.05$ as significant.
\end{abstract}

Results: A total of 101patients were studied with a mean age of $35.95 \pm 4.65$ years. In patients undergoing hysterosalpingography(HSG) and hysteroscopy(HSC), moderate/severe pain was experienced in 94(93.07\%) for HSG and 53(52.48\%) for Hysteroscopy with 12.15 times odds to experience moderate/ severe pain among patients with HSG (OR=12.15; p=0.001; 95\%CI: 5.14-28.78). Among patients that had mild pain experienced during Hysteroscopy, 47(97.92\%) preferred Hysteroscopy as against $1(2.08 \%)$ who preferred Hysterosalpingography (P-value $<0.001)$. Twenty- one (39.06\%) who had moderate/severe pain during Hysteroscopy preferred neither methods while among those who had done hysterosalpingography and had moderate/severe pain $69(43.40 \%)$ preferred Hysteroscopy as against 5(5.53\%) who preferred HSG. (P-value <0.001).

Conclusion: Patients experience various degrees of pain during endometrial evaluation. Hysterosalpingography is associated with more pain compared to office hysteroscopy. Patients based on their pain experience will prefer Hysteroscopy in the assessment of endometrial pathologies during infertility workup. There is a need for pain alleviation in these patients undergoing these procedures.

\section{Introduction}

Both Hysterosalpingography and Hysteroscopy are novel methods of endometrial evaluation, especially in women being managed for infertility and abnormal vaginal bleeding $[1,2]$. Hysterosalpingography is the routine investigation for endometrial cavity evaluation in most women in many centers during fertility evaluation, as in this center. It delineates endometrial pathologies and tubal patency [24]. Hysteroscopy is the gold standard for delineating anatomical/ structural pathologies of the endometrium. It has been used to confirm diagnosis of endometrial pathology. Diagnostic Hysteroscopy offers a more accurate diagnosis than Hysterosalpingography in detecting endometrial pathologies [5,6]. Hysterosalpingography still remains the best method to detect tubal pathologies [3]. High cost, pain and skilled manpower to perform the diagnostic hysteroscopy are known drawbacks to the procedure [3].

These two useful methods in the evaluation of the endometrial cavity employ the introduction of substances into the endometrium to cause endometrial distension. This process involves the introduction of vaginal speculum to visualize the external cervical ostium; the ectocervix is held with a Vorselum forceps to stabilize the cervix and enhance the introduction of another instrument (a cannula or hysteroscope) for introduction of the liquid to causes endometrial distension. Any of these steps outlined above could result into significant pain to the patient [7]. The endometrial distension is reportedly the most painful step either of the two processes [8]. In diagnostic Hysteroscopy these days, the process of identifying and stabilizing the cervix can be bypassed using a vaginoscopic ("non touch") approach where the hysteroscope is introduced into the endometrial cavity without the use of a vaginal speculum or vorselum forceps. The use of miniaturized hysteroscopes with narrower diameters $(<3.5 \mathrm{~mm})$ is known to reduce the pain at Hysteroscopy [8-11]. Hysterosalpingography utilizes either an oilbased or water-based contrast media for endometrial enhancement. The water-based contrast media is known to cause less pain than the oilbased media and therefore is used in most centers [12-14]. Diagnostic hysteroscopy utilizes either $\mathrm{CO}_{2}$ gas or normal saline infusion for endometrial distension. Studies indicate that $\mathrm{CO}_{2}$ causes less pain and gives better vision. However, most diagnostic hysteroscopies are carried out with normal saline as it provides better view and increases confidence $[15,16]$.

${ }^{\star}$ Correspondence to: Nyengidiki K Tamunomie, Department of Obstetrics and Gynaecology, University of Port Harcourt Teaching Hospital, Port Harcourt, Nigeria, E-mail: tammynyengs@yahoo.com

Received: April 03, 2020; Accepted: April 24, 2020; Published: April 29, 2020 
Studies have identified pain as a major drawback to either of the procedures. The willingness of the female spouse to undergo or repeat either of these two procedures is affected by the perceived pain that will occur during the procedure. This study is designed to understand patients' pain perception at either Hysterosalpingography or Hysteroscopy and acceptability of either of these procedures over the other.

\section{Methodology}

This was a cross-sectional prospective study conducted among infertile women at the University of Port Harcourt Teaching Hospital from $1^{\text {st }}$ of December 2018 to $31^{\text {st }}$ of July 2019. All women being assessed for infertility were enrolled while women who withheld consent for inclusion in the study, women with cervicitis or active pelvic infection, allergy to contrast and genital tract cancers, such as cervical or endometrial cancer were excluded.

The sample size was determined with $\mathrm{n}=\mathrm{N} / 1+\mathrm{N}(\mathrm{e})^{2}$; Where $\mathrm{n}$ = sample size, $\mathrm{N}$ = was the average number of new cases of infertility seen at the gynaecologic clinic over a period of six months, with $d=$ margin of error or precision expected (0.05). The sample size thus calculated was 92 allowing a 10\% attrition rate, the sample size for the study was therefore increased to 101 women. Women attending the gynaecology clinic of the University of Port Harcourt Teaching Hospital for infertility that satisfied the eligibility criteria and consented to the study were recruited for outpatient diagnostic office Hysteroscopy and Hysterosalpingography as they present until the required sample size was obtained. Socio-demographic data were collected through a prestructured questionnaire. These data collected included age, level of education, marital status, parity and the type of infertility. Outpatient diagnostic Hysteroscopy was performed between the $5^{\text {th }}$ and the $10^{\text {th }}$ day of the proliferative phase of the menstrual cycle by the principal investigators. Vaginoscopic "non-touch" technique using a $2.9 \mathrm{~mm}$ continuous flow $30^{\circ}$ rigid office hysteroscopy with a $2 \mathrm{~mm}$ telescope (Bettocchi Office Hysteroscope; Karl Storz GmbH \& Co., Tuttlingen, Germany) was used. For each hysteroscopic procedure, about $300 \mathrm{mls}$ of normal saline was used as a distension medium at a flow delivery pressure of $100 \mathrm{~cm} \mathrm{H}_{2} \mathrm{O}$. This pressure was achieved using an infusion pump (C-Fusor $1000 \mathrm{Mx} 4810$ by Smiths Medicals). No analgesic agents were administered to the patients before each procedure was conducted. Within 10 minutes of completing the hysteroscopy procedure, participants were asked to rate their pain experience using the Numerical Rating Pain Scale (NRPS) [17]. The patients were asked to score their pain perception from 0 to 10 during the procedure using the proposed classification ( 0 -No discomfort; $1-3=$ mild pain; $4-6=$ Moderate pain; $7-10=$ Severe pain). Participants were asked if the pain experience was enough to prevent them from repeating the procedure in the nearest future if asked to and the response was also collated. Following Hysteroscopy, Hysterosalpingography was done in the same cycle between the $7^{\text {th }}$ and the $11^{\text {th }}$ day. The procedure was done by the Radiologist with the Gynaecologist in attendance. The procedure was explained to the patient. The patient was then placed in the lithotomy position, and control film which is a plain film of the pelvis was taken. A bivalve speculum was used to expose the cervix. The vagina and the cervix were cleaned by chlorhexidine solution. The anterior lip of the cervix was grasped with a tenaculum; Leech Wilkinson cannula was introduced and stabilized in the cervix. Radio-opaque contrast medium $10 \mathrm{mls}$ (Urograffin by Bayer UK) was introduced through the cannula into the uterus. Under fluoroscopic guidance, filling of the uterine cavity and passage of the radio-opaque solution into the fallopian tubes and its spill from the fimbriae end was observed and documented with serial x-ray film. The Numerical Rating Scale (NRS) was used for pain assessment after 10minutes of the procedure. The patients were asked to score their pain perception from 0 to 10 during the procedure using the proposed classification $(0=$ no discomfort; $1-3=$ mild pain; $4-6=$ moderate pain; $7-10=$ severe pain). The patients were asked to state their preference following the completion of the two procedures based on their pain perception.

Socio-demographic variables, pain experience categorization for both Hysteroscopy and Hysterosalpingography were statistically analyzed using IBM SPSS 20 statistical software package. Descriptive statistics were computed for all relevant data and presented in tabular form. A comparison of pain against preference method for endometrial cavity evaluation for both methods using a McNemar Chi-square test and bivariate logistic regression analysis was conducted with $\mathrm{P}$ value less than 0.05 as significant.

\section{Ethical approval}

Approval for the study was obtained from the Ethics Committee of the University of Port Harcourt Teaching Hospital with number UPTH/ ADM/90/s.11/VOL.XI/710. Written informed consent was obtained from the patient before enrolment for the study. The basic ethical principle of autonomy, non-maleficence, beneficence, justice, veracity and scientific validity was strictly adhered to throughout the study.

\section{Results}

A total of 101patients were involved in the study with a mean age of $35.95 \pm 4.65$ years. Sixty -six $(65.35 \%)$ patients were in the age group 30 -39 years, $25(24.75 \%)$ in the age group $40-49$ years and $9.90 \%$ in age group 20-29years. Most of the patients had had tertiary level of education $62(61.39 \%)$ with only $8(7.92 \%)$ having primary education. Concerning parity of the patients $82(81.19 \%)$ are either nulliparous or primiparous. $82(81.19 \%)$ had secondary infertility while $18.18 \%$ (18) had primary infertility. This is indicated in Table 1.

Table 2 showed the relationship between educational status and pain perception: Among patients that had hysteroscopy, 48 (47.53\%) had primary education while $53(52.47 \%)$ persons had secondary/ tertiary education. Among those with primary education one $(2.08 \%)$ had mild pain while 47 (97.92\%) had moderate/severe pain. Among secondary /tertiary level of education patients 7 (13.21\%) had mild pain as against $46(86.79 \%)$ with moderate /severe pain $(0 \mathrm{R}=0.14, \mathrm{P}=0.04$ ;95\% CI 0.02-1.82).Patients that had hysterosalpingography with mild pain $1(2.08 \%)$ had primary education while 7 (97.92\%) had secondary/ tertiary education while those with moderate/severe pain $6(46.15 \%)$ had primary education while 7 (53.85\%)had secondary/tertiary education. Those with moderate/severe pain $6(6.45 \%)$ had primary education while 87 (93.55\%) had secondary/tertiary education $(\mathrm{OR}=$ 2.02, $\mathrm{P}=0.42 ; 95 \%$ CI 0.22-19.71).

Table 3 showed that in patients undergoing Hysterosalpingography (HSG), 94 (93.07\%) experienced moderate/severe pain while 7 (6.93\%) had mild pain. Same patients that had office hysteroscopy 53 (52.48\%) had moderate/severe pain with $48(47.52 \%)$ having mild pain. There is a statistically significant association observed between pain perception and the method used, as respondents who underwent HSG had a higher significant proportion for moderate/severe pain compare to those who did HSC (93.07\% vs. $52.48 \%$; $\mathrm{p}=0.001)$. The bivariate logistic regression analysis showed that respondents who underwent Hysterosalpingography were 12.15 times more likely to experience 
Nyengidiki Tamunomie K (2020) Comparative study of pain perception among infertile women undergoing Hysterosalpingography and Office Hysteroscopy in Port Harcourt, Nigeria

moderate/ severe pain compared to respondents who did Hysteroscopy (HSC) $(\mathrm{OR}=12.15 ; \mathrm{p}=0.001 ; 95 \% \mathrm{CI}: 5.14-28.78)$.

Among patients undergoing Hysteroscopy when asked their preferred method in relation to the pain experience $47(97.92 \%)$ preferred Hysteroscopy as against $1(2.08 \%)$ who preferred Hysterosalpingography (Pvalue $<0.001)$. Twenty- one $(39.06 \%$ ) who had moderate/severe pain during Hysteroscopy preferred neither methods while among those who had Hysterosalpingography and had moderate/ severe pain $69(73.40 \%)$ preferred Hysteroscopy as against $5(5.53 \%)$ who preferred Hysterosalpingography. In addition, 20 (21.28\%) who had severe pain preferred neither methods of endometrial evaluation ( $\mathrm{P}$ value $<0.001$ ). Irrespective of the method, the preference for HSC is still statistically significantly higher for mild and moderate/severe pain categories. These are stated in Table 4.

\section{Discussion}

Most outpatient procedures in the evaluation of the endometrial cavity are done without any form of analgesia or anaesthesia [18-20] based on the assumption that they are of short duration and patients can bear the discomfort these procedures can cause them. In the evaluation of the endometrial activity the commonest means in most resource limited centres is the use of the Hysterosalpingography which proffered the added advantage of delineating the fallopian tubes among infertile patients [3,4]. However, recourse to the use of Hysteroscopy as the gold standard is beginning to be the norm in recent times. Pain, an unpleasant experience has been a major factor mitigating against the use of the above methods. In this study, it was noted that most of the patients that had at least a secondary level of education had a twofold increase in moderate/severe pain during Hysterosalpingography while that was not noticed during Hysteroscopy even though almost equal numbers of the educational divide had moderate/severe pain. It is probable that pre-procedure health literacy information obtained by the patients may have influenced their perception [21].The perception of pain has been associated with the level of education of a patient and it is said that the higher the educational level, the lesser the pain perception. This had been explained by Köppen et al who stated in their work that health literacy is easily achieved in one with education. It was

Table 1. Characteristics of patients undergoing Hysteroscopy and Hysterosalpingography

\begin{tabular}{|c|c|c|c|}
\hline Characteristics & Variables & Frequency & Percentage \\
\hline $\begin{array}{c}\text { Age } \\
\text { Mean age }\end{array}$ & $\begin{array}{c}20-29 \\
30-39 \\
40-49 \\
35.95 \pm 4.65 \text { years }\end{array}$ & $\begin{array}{l}10 \\
66 \\
25\end{array}$ & $\begin{array}{l}9.90 \\
65.35 \\
24.75\end{array}$ \\
\hline Educational level & $\begin{array}{l}\text { Primary } \\
\text { Secondary } \\
\text { Tertiary }\end{array}$ & $\begin{array}{c}8 \\
31 \\
62 \\
\end{array}$ & $\begin{array}{c}7.92 \\
30.39 \\
61.39\end{array}$ \\
\hline Parity & $\begin{array}{l}0-1 \\
2-3 \\
4-5\end{array}$ & $\begin{array}{c}85 \\
15 \\
1\end{array}$ & $\begin{array}{c}84.16 \\
14.85 \\
0.99\end{array}$ \\
\hline Infertility & $\begin{array}{l}\text { Primary } \\
\text { Secondary }\end{array}$ & $\begin{array}{l}19 \\
82\end{array}$ & $\begin{array}{l}18.81 \\
81.19\end{array}$ \\
\hline
\end{tabular}

Table 2. Educational status and relationship to pain perception during Hysteroscopy and Hysterosalpingography

\begin{tabular}{|c|c|c|c|c|c|}
\hline \multirow{2}{*}{\multicolumn{2}{|c|}{ Pain perception }} & \multicolumn{2}{|c|}{ Level of Education } & \multirow{2}{*}{$\begin{array}{c}\chi^{2} \\
(p \text {-value })\end{array}$} & \multirow{2}{*}{$\begin{array}{c}\text { OR } \\
(95 \% \mathrm{CI})\end{array}$} \\
\hline & & \multirow{2}{*}{$\begin{array}{c}\text { Primary } \\
1\end{array}$} & \multirow{2}{*}{$\begin{array}{c}\text { Secondary/Tertiary } \\
7\end{array}$} & & \\
\hline \multirow{2}{*}{ Hysteroscopy } & Mild & & & \multirow{2}{*}{$\begin{array}{c}4.27 \\
(0.04)\end{array}$} & \multirow{2}{*}{$\begin{array}{c}0.14 \\
(0.02-1.82 \\
\end{array}$} \\
\hline & Moderate/Severe & 47 & 46 & & \\
\hline \multirow{2}{*}{ Hysterosalpingography } & Mild & 1 & 7 & \multirow{2}{*}{$\begin{array}{c}0.42 \\
(0.52)\end{array}$} & \multirow{2}{*}{$\begin{array}{c}2.07 \\
(0.22-19.71)\end{array}$} \\
\hline & Moderate/Severe & 6 & 87 & & \\
\hline
\end{tabular}

Table 3. Comparison of Pain Perception between Hysterosalpingography and Hysteroscopy

\begin{tabular}{|c|c|c|c|c|c|c|}
\hline \multirow[t]{2}{*}{ Method } & \multicolumn{2}{|c|}{ Pain Perception } & \multirow[t]{2}{*}{ Total (\%) } & \multirow[t]{2}{*}{$d f$} & \multirow[t]{2}{*}{$\begin{array}{c}\chi^{2} \\
(p-v a l u e)\end{array}$} & \multirow[t]{2}{*}{$\begin{array}{c}\text { OR } \\
(95 \% \mathrm{CI})\end{array}$} \\
\hline & Moderate/Severe & Mild & & & & \\
\hline $\begin{array}{l}\text { Hysterosalpingography } \\
\text { (HSG) }\end{array}$ & 94 (93.07) & $7(6.93)$ & $101(100)$ & & \multirow{2}{*}{$\begin{array}{c}39.97 \\
(0.001)^{*}\end{array}$} & \multirow{2}{*}{$\begin{array}{c}12.16 \\
(5.14-28.78)\end{array}$} \\
\hline Hysteroscopy (HSC) & $53(52.48)$ & 48 (87.27) & $101(100)$ & 1 & & \\
\hline
\end{tabular}

*Statistically significant $(p<0.05)$

Table 4. Comparison of Pain Perception between HSC and HSG against preference

\begin{tabular}{|c|c|c|c|c|c|}
\hline \multirow{2}{*}{ Pain Categorization } & \multicolumn{3}{|c|}{ Preference } & \multirow{2}{*}{$d f$} & \multirow{2}{*}{$\underset{(p-v a l u e}{\chi^{2}}$} \\
\hline & HSC & HSG & NONE & & \\
\hline $\begin{array}{c}\text { HSC } \\
\text { Mild (48) } \\
\text { Moderate-severe (53) } \\
\text { Total } 101\end{array}$ & $\begin{array}{c}47(97.92) \\
25(47.17) \\
72\end{array}$ & $\begin{array}{c}1(2.08) \\
7(13.21) \\
8\end{array}$ & $\begin{array}{c}0(0.00) \\
21(39.06) \\
21\end{array}$ & 2 & $32.05(0.001)$ \\
\hline $\begin{array}{c}\text { HSG } \\
\text { Mild (7) } \\
\text { Moderate-severe (94) } \\
\text { Total } 101\end{array}$ & $\begin{array}{c}3(42.86) \\
69(73.40) \\
72\end{array}$ & $\begin{array}{c}3(42.86) \\
5(5.32) \\
8\end{array}$ & $\begin{array}{c}1(14.29) \\
20(21.28) \\
21\end{array}$ & 2 & $12.60(0.001)$ \\
\hline
\end{tabular}


Nyengidiki Tamunomie K (2020) Comparative study of pain perception among infertile women undergoing Hysterosalpingography and Office Hysteroscopy in Port Harcourt, Nigeria

noted in their study that pain perception is reduced in the presence of health literacy which provides increase opportunities/information for pain management [21].

In the review of the women pain perception against the method of endometrial cavity evaluation, there was an observed twelvefold increase in moderate/severe pain perception among women who had Hysterosalpingography as against Hysteroscopy. This observation is congruent to that by Carvalho et al who noted a $63.95 \%$ in perception severe /moderate pain among patients having HSG [22] and that of Delaco et al who noted a $36.05 \%$ same degree of pain in patients undergoing office hysteroscopy [23]. This is however at variant with the findings of Brayboy et al who observed that both pre-procedure and post-procedure pain perceptions are higher among patients undergoing office hysteroscopy as against those that had hysterosalpingography [24]. However, it not stated whelter a "non- touch technique" was used in this study which had been known to reduce the pain experience in most patients $[25,26]$. Other reasons for pain in the two procedure include handling of the cervix with a vorsellum, oil based versus waterbased distension media, pressure of fluid introduction into the uterus in hysteroscopy and operators' skills $[7,8]$.

There is a statistically significant preference for Hysteroscopy against Hysterosalpingography among women who had evaluation of the endometrial cavity for infertility in the study. This was noted irrespective of the grading of pain perception of the patients. The need for a "near no pain" experience is evident in nearly all patients having mild pain during office hysteroscopy wanting to repeat the procedure if need be and a significant proportion not wanting to repeat either procedures because of moderate/severe pain experienced. The visual participation of the patients during Hysteroscopy may pay a role in the reduced pain perception as against that noted during Hysterosalpingography. This assertion is supported by findings of Carwile et al. where visual distractions techniques have been noted to contribute to reduce pain experience [27] since most of the patients undergoing were told to look at the screen during the procedure. Pain perception obviously had affected the patient choice for a repeat procedure and choice of procedure. In a study by Parry et al where Hysterosalpingography was used to assess tubal patency against parryscope technique using Hysteroscopy about $92 \%$ of patients strongly preferred Hysteroscopy associated with minimal pain as against hysterosalpingography [28].

This study is largely descriptive and did not take into consideration possible confounders in the causation of pain during both procedures for the evaluation of the uterine cavity. There is thus need to look at possible predictors of pain perception among this group of women.

In conclusion, the observed trend in pain experience in this study call for the need for healthcare providers to have a new mindset to address the pain alleviations needs of their patients to ensure acceptability of Hysterosalpingography in our environment, since it is the commonest investigative tool for endometrial pathologies . It also brings to bear that even though office hysteroscopy is usually marketed as painless and preferred by the patients, there is also a need to address the pain needs of patients who may be privileged to have this method of endometrial evaluation to sustain patronage and ensure a better patient experience.

\section{Data availability}

The data used to support the findings of this work are available from the corresponding author on request

\section{Funding} work

The funding of this study was entirely done by the authors of this

\section{Conflict of interest}

Nil

\section{References}

1. Deffieux X, Gauthier T, Menager N, Legendre G, Agostini A, et al. (2014) Hysteroscopy: guidelines for clinical practice from the French College of Gynaecologists and Obstetricians. Eur J Obstet Gynecol Reprod Biol 178: 114-122. [Crossref]

2. Bello TO (2004) Pattern of tubal pathology in infertile women on Hysterosalpingography in Ilorin, Nigeria. Annals African Med 3: 77-79.

3. Eng CW, Tang PH, Ong CL (2007) Hysterosalpingography: current applications. Singapore Med J 48: 368-373.

4. Onwuchekwa CR, Oriji VK (2017) Hysterosalpingographic (HSG) pattern of infertility in women of reproductive age. J Hum Reprod Sci 10: 178-184. [Crossref]

5. Wang CW, Lee CL, Lai YM, Tsai CC, Chang MY, et al. (1996) Comparison of Hysterosalpingography and Hysteroscopy in female infertility. J Am Assoc Gynecol Laparosc 3: 581-584. [Crossref]

6. Prevedourakis C, Loutradis D, Kalianidis C, Makris N, Aravantinos D (1994) Surgery: Hysterosalpingography and Hysteroscopy in female infertility. Human Reprod 9: 23532355 .

7. Favilli A, Grasso M, Gerli S, Mazzon I (2018) How to overcome a resistant cervix for hysteroscopy. Hysteroscopy 47-57.

8. Cooper NA, Smith P, Khan KS, Clark TJ (2010) Vaginoscopic approach to outpatient Hysteroscopy: a systematic review of the effect on pain. BJOG 117: 532-539. [Crossref]

9. Cicinelli E (2005) Diagnostic minihysteroscopy with vaginoscopic approach: rationale and advantages. J Minimal invasive Gynecol 12: 396-400. [Crossref]

10. Oraif A (2016) Diagnostic hysteroscopy in a procedure room setting compared to diagnostic Hysteroscopy in the operating room. Int J Reprod Contracep Obstet Gynecol 5: 4164-4173.

11. Cicinelli E (2010) Hysteroscopy without anaesthesia: review of recent literature. $J$ Minim Invasive Gynecol 17: 703-708.

12. Van Rijswijk J, Van Welie N, Dreyer K, Tajik P, Lambalk CB, et al. (2019) Tubal flushing with oil-or water-based contrast medium: can we identify markers that indicate treatment benefit? Hum Reprod Open. [Crossref]

13. Wang R, Van Welie N, Van Rijswijk J, Johnson NP, Norman RJ, et al. (2019) The effectiveness of tubal flushing with different contrast media on fertility outcomes: a systematic review and network meta-analysis. Ultrasound Obstet Gynecol 54: 172-181

14. Roest I, Van Welie N, Mijatovic V, Dreyer K, Koks CA, et al. (2020) Safety of oil-based contrast medium for Hysterosalpingography: a systematic review. Hum Reprod Open.

15. Raimondo G, Raimondo D, D'Aniello G, Russo C, Ronga A, et al. (2010) A randomized controlled study comparing carbon dioxide versus normal saline as distension media in diagnostic office hysteroscopy: is the distension with carbon dioxide a problem? Fertil Steril 94: 2319-2322. [Crossref]

16. Cooper NA, Smith P, Khan KS, Clark TJ (2011) A systematic review of the effect of the distension medium on pain during outpatient Hysteroscopy. Fertil Steril 95: $264-$ 271. [Crossref]

17. Mathias H, Achim E (2006) Pain assessment. Eur Spine J 15(Suppl1): S17-S24 [Crossref]

18. Bettochi S, Ceci O, Nappi DR, Mascipinto V, Pansini V et al. (2004) Operative Office Hysteroscopy without anaesthesia,analysis of 4863 cases performed with mechanical instruments. J Am Assoc Gynecol Laparosc 11: 59-61. [Crossref]

19. Pados G, Makedos A. Office hysteroscopy Endoscopy-Innovative uses and emerging Technologies Somchai Amornytin Edited Intech Open Doi:10.5772/60658. Available from http:// www.intechopen .com/books aaccessed $18.00 \mathrm{hrs}$ on $26^{\text {th }}$ February 2020.

20. Duffy JM, Ahmad G, Watson AJ (2008) Pain relief during Hysterosalpingography: a national survey. Hum Fertil (Camb) 11: 119-121. [Crossref]

21. Köppen PJ, Dorner TE, Stein KV, Simon J, Crevenna R (2018) Health literacy, pain intensity and pain perception in patients with chronic pain. Wien Klin Wochenschr 130 23-30. [Crossref] 
Nyengidiki Tamunomie K (2020) Comparative study of pain perception among infertile women undergoing Hysterosalpingography and Office Hysteroscopy in Port Harcourt, Nigeria

22. de Carvalho Schettini JA, Ramos de Amorim MM, Ribeiro Costa AA, Albu-querque Neto LC (2007) Pain evaluation in outpatients undergoing diagnostic anesthesia-free Hysteroscopy in a teaching hospital: a cohort study. J Minim Invasive Gynecol 14: 729-735. [Crossref]

23. De Iaco P, Marabini A, Stefanetti M, Del Vecchio C, Bovicelli L (2000) Acceptability and pain of outpatient Hysteroscopy. J Am Assoc Gynecol Laparosc 7: 71-75.

24. Brayboy LM, Murphy EM, Cohen JD, Somkuti SG, Sobel M, et al. (2010) Patient pain perception with Hysterosalpingography versus hysteroscopy infertility evaluation. Fertil Steril 94: 225.
25. Natalia E, Desiree F, Ashley DT, Sarah R, Jose C (2019) Vaginoscopy "No Touch" technique: a feasible alternative to paracervical block for in office hysteroscopy obstetrics \& gynecology.

26. Murat E, Levent Y, Sedat A (2009) Comparison of vaginoscopic no touch method with the traditional method of outpatient hysteroscopy. Med J of Bakirköy 5: 63-66.

27. Carwile JL, Feldman S, Johnson NR (2014) Use of a simple visual distraction to reduce pain and anxiety in patients undergoing colposcopy. $J$ Low Genit Tract Dis 18: 317 321. [Crossref]

28. Parry JP, Riche D, Rushing J, Linton B, Butler V, et al. (2017) Performing the Parryscope technique gently for office tubal patency assessment. Fertil Steril 108: 718. [Crossref]

Copyright: (C2020 Nyengidiki Tamunomie K. This is an open-access article distributed under the terms of the Creative Commons Attribution License, which permits unrestricted use, distribution, and reproduction in any medium, provided the original author and source are credited. 